Frontiers: The Interdisciplinary Journal of Study Abroad Volume 32, Issue 2, pp. 94-119

(C) Kristin L. Thomas \& Deborah L. Kerstetter This work is licensed under the Creative Commons Attribution-NonCommercial-

\title{
The Awe in Awesome in Education
}

\section{Abroad}

\author{
Kristin L. Thomas ${ }^{1}$ \& Deborah L. Kerstetter ${ }^{1}$
}

\begin{abstract}
Few have examined how students perceive or make sense of their formal educational travel experiences, resulting in a dearth of knowledge about perceived educational value of experiences. To rectify this situation, this study addressed how students make meaning during their education abroad (EA) experience. Employing a constructivist grounded theory approach, students were found to process their experiences through four meaning-making structures labeled, "Seeking Novelty," "Actually Being," "Securing/Blending," and "Living in a State of Awe," all of which contributed to experiencing awe during their EA experience. The authors propose the Education Abroad Meaning-Making Framework, which can be used to understand students' experiences while on EA and to serve as a theoretical foundation upon which further research on EA can be conducted. They also discuss implications of the Framework for pre- and post-experience advising, program, and curriculum development.
\end{abstract}

\section{Abstract in French}

Peu d'études ont examinées comment les étudiants perçoivent et donnent du sens aux expériences formelles durant leurs voyages éducatifs, résultant en un manque de connaissance quant à la valeur perçue de ces expériences. Afin de rectifier cette situation, cette étude décrit comment les étudiants donnent du sens à leurs expériences durant leurs voyages éducatifs (VE). Utilisant une approche théorique constructiviste, il est apparu que les étudiants traitent leurs

1 The Pennsylvania State University, University Park, USA

Corresponding author: Kristin L. Thomas, The Pennsylvania State University, email: klt16@psu.edu 
expériences à travers quatre structures donneuses de sens appelées « Chercher la nouveauté », « Être vraiment », «Confort/Immersion », et « Vivre émerveillé », qui ont toutes contribuées à leur émerveillement durant leurs VE. Les auteurs proposent le Cadre de Voyage Éducatif Donneur de Sens, qui peut être utilisé pour comprendre les expériences des étudiants pendant leur VE et servant de fondement théorique sur lequel baser de futures recherches sur les VE. Ils discutent aussi des implications de ce Cadre pour le développement de l'encadrement, du programme et du curriculum avant et après les VE.

\section{Keywords:}

Study abroad, Education abroad, Awe, Learning, Meaning-making

"Universities need to do a better job to ensure that students understand that study abroad programs are more than just a chance to have a good time"

(Relyea, Cocchiara, \& Studdard, 2008, p. 346).

"Short-term EA programs are at best tourism with a course number attached"

(Sutton, Miller, \& Rubin, 2007, p. 25).

In the wake of skepticism about education abroad, practitioners and scholars have made admirable strides to establish and maintain the integrity of education abroad. In 2004 The Forum on Education Abroad published Standards of Good Practice for Education Abroad. As the standards development organization for the field, the Forum has seen a rise in institutional membership since forming in 2001, indicating an increase in commitment to high standards for Education Abroad (EA) (The Forum on Education Abroad, 2017b). Despite these accomplishments, EA is still plagued by criticism, such as that which is noted in the opening; educators' perceptions that any touristic involvement renders EA shallow; and students' indiscriminate description of their EA experience as "awesome." In a recent study, more than $40 \%$ of EA practitioners reported that they were either somewhat or very concerned with the disparity between student expectations and the reality of the experience, and helping students maximize their EA experiences and academic quality (The Forum on Education Abroad, 2017a), among other issues. Hence, we contend that EA is highly misunderstood. A more nuanced understanding of how students perceive or make sense of their 
EA experience is necessary to reduce the knowledge gap regarding experiences that have educational value, including those involving travel and tourism (T\&T).

Much of what is known about EA students' experiences has been derived through quantitative assessments of learned outcomes such as language learning, intercultural competence, intellectual or cognitive development, affective development and social growth, long-term effects, and career impact (Meyer-Lee \& Evans, 2007; Twombly, Salisbury, Tumanut, \& Klute, 2012). This is problematic because understanding what "experiences mean is difficult if not impossible with quantitative methods..." (Andereck, McGehee, Lee, \& Clemmons, 2011, p. 84). We adopted an interpretivist approach to address the overall study purpose, which is to assess how students interpret or make sense (a.k.a. meaning-making) of their EA experience.

Observing meaning-making through reflection, EA has been viewed in relation to the interventions that professionals either use or advocate for in order to aid transformative learning (Allen, 2009; Geiser, 2015; Hall et al., 2016; Kiely, 2004; Vande Berg, Paige, \& Lou, 2012). Wong (2015) argues that educators should rethink interventions considering that one of the underlying premises of interventions is that recipients (i.e., students) "are incapable of seeing and making sense of their experiences without outside help (p. 129)." According to Kegan (1982), humans construct their own reality based on perceptions and, as a result, there is no experience absent of meaning-making. Thus, students make meaning with and without interventions. Not fully exploring how students interpret (i.e., make meaning of their own EA experience) without interventions has left a gap in holistically understanding students' perceived educational value of EA experiences. Therefore, the research question guiding this study was, "How do students make meaning during their EA experience?” Results will aid practitioners and researchers in understanding how students make sense/meaning of their EA experience sans intervention, contributing to theory about and practices associated with EA.

Following is a description of the method associated with this study, a proposed Framework describing and explaining how students make meaning during EA, a discussion about the results, and implications for EA research and programs.

\section{Method}

Our thinking was informed by Baxter-Magolda and King's (2012) rendering of Kegan's orders of consciousness. According to Kegan (1982), individuals organize and make sense of their perceptions (i.e., make meaning) by employing patterns of interpretation called "forms" or "meaning-making 
structures." Forms are observed in the ways individuals' structure their arguments, which illustrate what they view as important, as well as the rationale for their decisions, beliefs and approaches. "Forms reflect how we think (structure), rather than what we think (content)" (Baxter Magolda \& King, 2012, p. 7).

For example, two voters might endorse the same referendum outcome (content) but for two different reasons (structure). One might focus solely on whether the referendum personally benefits her, while the other might focus on the benefits to the community regardless of whether he would personally benefit; each reflects a different way of framing the argument and basis for choosing how to vote. (Baxter Magolda \& King, 2012, p. 7)

The belief that students employ their own patterns of meaning-making strategies led us to adopt a constructivist grounded theory approach to answer the study's research question-

How do students make meaning during their EA experience?

\section{Constructivist Grounded Theory as the Form of Inquiry}

Constructivist Grounded Theory (CGT) is an inductive form of inquiry in which theory about a social or social-psychological process is generated or derived from the data. Using CGT is appropriate when there is no existing theory explaining the process of meaning construction in the same context or with a similar population (Creswell, 2012, p. 88). In more common approaches to and presentations of research, a literature review is conducted, hypotheses or research questions are developed and presented, data is collected and analyzed, results are presented, and conclusions are drawn. With CGT, what is observed in the field shapes data collection and informs data analysis, which occurs simultaneously. For example, researchers focus on participants' actions and processes instead of descriptive themes, and then create abstract analytical action categories by constantly comparing and identifying variations in the categories with the goal of developing a preliminary theoretical framework (Charmaz, 1990). This is followed by a literature review. Delaying the literature review until after data collection allows researchers to situate the study within the literature. In this study the results are presented through a draft of a theoretical framework, which builds on the concepts generated from the data as well as existing literature.

\section{Sample}

A sample of 10 students was drawn from a population of 126 EA students who had participated in the first phase of a larger study (i.e. on-line 
survey about their EA experience). All were enrolled in some type of EA program (semester-long, direct enroll, faculty-led) during spring 2016. Of the 10, 2 were male and 8 were female. All but one female were studying abroad in France, Spain, Italy, Germany, England, or Morocco at the time of the study. According to Charmaz (2014), conducting interviews with a small number of individuals is acceptable if the results lead to robust categories and themes and theoretical saturation.

\section{Data Collection and Analysis}

In January 2016, the first author e-mailed the 126 students who had completed the on-line survey, reminding them about this phase of the studyin-depth interviews. In February 2016, after students had departed for their EA experience and were abroad, the first author sent a second email requesting times of availability and Skype username and confirming access to Wi-Fi. Twelve students responded; however, only ten were interviewed. Two students dropped out of the study due to schedule conflicts and technical challenges. Prior to each of the interviews, the first author sent students a Skype ${ }^{\circledR}$ collaboration invite and reminded them that the interview would be recorded using Amoloto Call Recorder ${ }^{\circledR}$. A custom coding system was created to maintain confidentiality and each interview was transcribed using a tablet application of Voice Record Pro®.

\section{In-depth Interview}

Baxter-Magolda and King's (2007) interview protocol was implemented because of its flexibility and goal of triggering relevant responses. First, the lead author opened each interview by reminding students of the purpose of the study, which was to learn about EA from their perspective, that there were no right or wrong responses, and that they would be contacted later to review the results and provide input. Then, because it is necessary that interviewees have "ready access to reflections" (Baxter-Magolda \& King, 2007, p. 496) and past experiences during interviews focused on assessing meaning-making, an email was sent approximately 15 minutes prior via Skype ${ }^{\circledR}$ message asking them to think about moments they had experienced during EA that made them feel excited, frustrated, in awe, or angry. These terms were introduced to students prior to the interview because they, in combination with good probing questions, produced productive content to examine meaning-making. For example, when students referenced an experience, the first author used probes such as "tell me more about that," "help me understand that more," or "what do you mean by that?" As Baxter-Magolda and King assert, this type of probing encourages participants to speak and have their "most important concerns... emerge freely" (p. 498). As noted earlier, CGT is a non-linear and 
iterative process. The process continues until theoretical saturation ${ }^{1}$ has been reached.

\section{Data Analysis}

Data analysis took place in three phases-initial coding, focused coding, and theoretical coding. It also included memo-writing, an integral aspect of CGT that begins with data collection and continues through coding and drafts of papers (Charmaz, 2014). After listening to the first three interviews to get a sense of them, the first author began transcribing, initial coding, and memowriting. Initial coding involved line-by-line coding for action and psychological processes (e.g., "feeling surreal") rather than themes (Charmaz, 1990) Next, during focused coding, both authors compared and re-evaluated the most useful initial codes to determine which codes could be collapsed and elevated into overarching, abstract analytical categories. For example, the initial codes "having new experiences," "wanting to meet new people," and "experiencing new culture" were collapsed into the focused code, "Seeking Novelty." Lastly, transcripts and memos were re-examined to further explicate "Seeking Novelty” from a focused code to a conceptual category.

\section{Establishing Trustworthiness and Credibility}

Trustworthiness and credibility were established by conducting followup interviews with the students and triangulating the data. All 10 students were asked to participate in a follow-up interview; 5 agreed to be interviewed. Individual face-to-face interviews were held in in private meeting rooms on the home university campus after students returned from their EA experience. The length between students return to campus and their follow up interview ranged from two to four months. Because time had passed, each student was initially asked to spend five minutes reflecting on their EA experience by free flow writing (i.e., typing about what the experience meant to him/her). Reflection is a commonly used tool to assist with recall and to understand meaning-making (Baxter Magolda \& King, 2007; Kiely, 2004; Lahey, Felix, Goodman, Kegan, \& Souvaine, 2011; Pagano Laura, 2009). Next, using a semistructured/conversational approach, students were asked to identify and expand on: a particular incident during EA that stuck with them; a moment during EA that they were not fond of or happy with; and a moment or moments during EA that made them feel "alive," "awesome," or like they couldn't believe they were there.

\footnotetext{
${ }^{1}$ Theoretical saturation is an exhaustion of ideas associated with a category (Charmaz, 2014, p. 199).
} 
The authors continued the iterative and comparative process established in the CGT design by comparing student statements in the followup interviews with the conceptual categories generated from the first set of interviews. Further, students were invited to review the conceptual categories during the post EA experience interviews. The analysis of students' comments and descriptions of their experiences, and their post-experience input corroborating the findings attested to the trustworthiness and credibility of the theoretical categories used to create the Education Abroad Meaning-Making Framework, a theoretical framework proposed in the following section used to describe students' meaning-making process while abroad.

\section{Revealed Meaning-Making Structures}

To document how students make meaning during their EA experience using the CGT form of inquiry, a review of the literature was conducted in relation to concepts generated from the data collection and analysis process. Because EA is a combined academic and travel and tourism (T\&T) experience, the T\&T, education, and education abroad literatures were examined.

Students indicated the purpose of EA was to experience and learn about other cultures, which coincides with T\&T scholars' findings that tourists travel for educational purposes and to experience different customs and cultures (Bos, McCabe, \& Johnson, 2015; Cohen, 1972; Crompton, 1979). Students processed, interpreted, and made sense of their EA experiences through three meaning-making structures-"Seeking Novelty," "Securing and Blending," and "Actually Being"-all of which led to "Living in a State of Awe." Figure 1 depicts the meaning-making structures uncovered and their relationships to each other.

To make sense of Figure 1-The Education Abroad Meaning Making Framework (EAMM)-first consider the universal symbol for nuclear fusion, which represents a complex process. In the nuclear fusion symbol, "the middle symbol represents the core of the atom (protons and neutrons), the rings around it represent the orbits of the electrons, and the circle [o]n the ring represents the electron" (Williams, 2018). When two protons are pushed together, there is a strong interaction, they amalgamate releasing energy (GRS Deutschland, n.d.). In the EAMM, the center represents the mind (the core or nucleus) of the student. The rings represent the meaning making structures"Novelty," "Securing and Blending," and "Actually Being" - which denote the non-linear flow of meaning-making. The Venn diagram at the center represents Keltner and Haidt's (2003) prototype for awe where vastness and students' inability to accommodate the experience (similar to the strong 
interaction between protons) result in Living in a State of Awe. The circles on the rings represent students' different experiences.

\section{FIGURE 1. EDUCATION ABROAD MEANING MAKING FRAMEWORK}

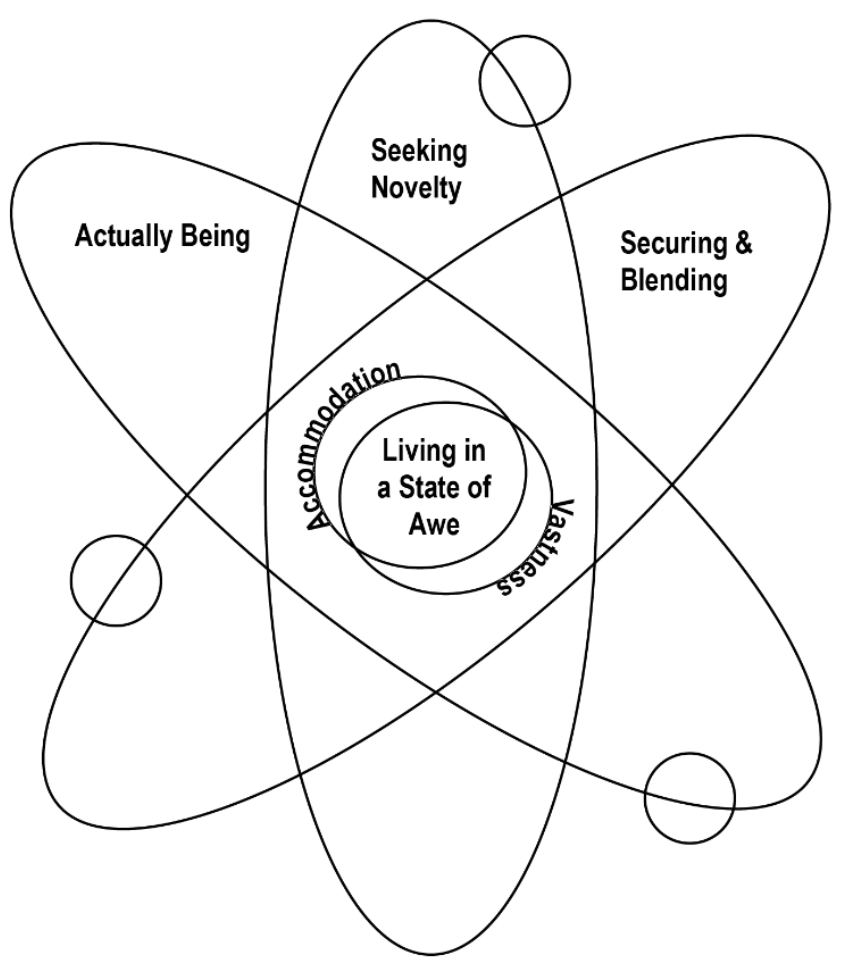

\section{Seeking Novelty}

Students' perceived seeing new cultures, having new experiences, and learning about new/different customs and people to be part of the purpose of EA. They sought and were ready to receive that which was new, including different customs and cultures, which Cohen (1972) suggests is the point of today's travel experience. Borrowed from psychology, the tourism literature refers to this notion as a search for novelty or something never encountered, not remembered nor related to any previous experiences, and/or something which evokes curiosity and natural inclinations toward exploration (Berlyne, 1950; Weisler \& McCall, 1976). Thus, in this study, the meaning-making structure "Seeking Novelty" is the act and mental process of taking in and grasping new information during EA. Students perceived and assessed novelty based on the degree to which experiences exposed them to the new and different; provided firsthand insight (i.e., primary knowledge) in ways that 
can't be attained at home; confirmed and challenged their ideas about the world; and had the potential of happening again.

Students went into their EA experience to get answers to their questions about the world. Their curiosity drove them to seek new information and knowledge that confirmed, challenged or provided further understanding:

I wouldn't say it's [hometown] the most cultured town in the world, [but]... in Europe... it is so cool to see how they respect each other and how they interact with each other... because... it's not quite the same thing in America... and that's something that drives me a little bit crazy.

This student felt "refreshed" and "enriched" by his perception that the world outside of his hometown (and thus home country) is more open minded. Alternatively, a student studying abroad in Morocco doubted the messages propagated by society, teachers and Western media about the Middle Eastern culture:

I had a hard time believing that any religion that actually legitimately looked to subdue women would have lasted this long... everyone's perception of Muslims [is] that they don't allow women to be educated... They [media, Western society] say that all the time.

She observed women being respected and obtaining an education, but also recognized that the "disparity between men and women... [is real...], men control public spaces and women don't." She reasoned, "It's not terribly unlike some more rural places in the U.S." Obtaining refreshing and reaffirming knowledge drove these students to continue to seek information and to learn. Novelty and strangeness are essential to the T\&T experience (Cohen, 1972). The fact that there is little benefit to seeking the norm while abroad as plainly depicted by a young man studying abroad in Germany: "I could just study in America, but that's the same culture I've always been in.” He and other students recognized that learning, preferably from novel sources in nontraditional settings, was essential to their EA experience supporting the notion that travel for education and learning takes place either formally or informally (Ritchie, Cooper, Hall, \& Timothy, 2009). Moreover, as Crompton (1992) found among tourists in general, not taking advantage of a novel, once in a lifetime opportunity was viewed as a lost educational opportunity.

Similar to results presented by Cohen (1972) who studied types of tourists, the amount and mode of novelty a student sought and/or was ready to receive differed. For example, one female chose her study abroad location for its cultural distance: 
It was that [Morocco] was different and I really wanted to experience Muslim culture... I think that the type of person who comes to Morocco is a little more intense than the average student. I think they definitely have to be more culturally aware in general of the value of separate cultures and things like that...

Conversely, another student sought more balance between novelty and familiarity. She chose Leeds because "it was... an English-speaking country..." She expressed, however, "Seeing the different places that are different from [location of college] or different from [home city] and just kind of getting a bigger view of the world is what I really want to do.” There was enough cultural distance that she could experience the world beyond her hometown. Satisfying their desire to experience something different, both students perceived their experiences as novel despite the difference in cultural distance between their homes and their EA host country.

In this study students differently sought and experienced the novelty of a new culture and unique customs, gaining knowledge along the way, which supports earlier research on EA students (Cardon, Marshall, \& Poddar, 2011; Nyaupane, Paris, \& Teye, 2010). T\&T researchers have associated novelty seeking with thrill, alleviating boredom, changing one's routine and surprise (Lee \& Crompton, 1992) as well as curiosity, experiencing the destination's atmosphere, and seeing a place rather than knowing of it vicariously; the latter being attributed educational value (Crompton, 1979; Pearce \& Lee, 2005). Zull (2012) suggested that novelty associated with EA is a missing element in academic learning environments. Falk, Martin and Balling (1978, p. 132) argued novelty in educational activities disrupts normal patterns of thinking during which students who are unfamiliar with the environment benefit from exploration and setting-oriented learning. In this study EA students valued and sought disruption by "Seeking Novelty."

\section{Securing and Blending}

According to Baxter Magolda and King (2008), identity influences meaning-making by impacting the interpretive process. In this study, the influence of identity was manifested through "Securing" and "Blending."

\section{Securing}

Students wanted to connect first-hand with the world through new experiences, but this was stressful for some. For example, some students were nervous about being away from family and friends: "I tried not to think about leaving because I knew if I thought about leaving I would, like, start to panic a little bit" and "I'm not going to see anybody that I really know for, like, two and 
half months!” These feelings were compounded for another student by the difference in the time zone and a series of unexpected mishaps leaving him unsure of which classes he could take and where to purchase kitchen supplies, so he could cook for himself. "That was difficult," he explained, "because, like, [for] the first week or two, I kind of felt, like, lonely [I felt like] oh gosh! I'm in an entirely different country where I don't know anybody, and I have to buy all these things!”

Students who expressed these sentiments, from now on referred to as "Securers," processed their experience through a sense of loss (e.g., not having friends, family, familiarity), identifying what they did not have, what would have been easier if they had stayed home, and were secure with their American identity. With time, they assessed their experiences based on their ability to provide familiarity, support and comfort, which helped them ease into the novelty of the experience. Support from family, friends, other American or co-national students abroad, and members of the host community, have previously been identified as beneficial and necessary to persevere through the EA experience (Bodycott, 2015; Kinginger, 2009). The spiritual and familial support helped Securers see the larger purpose of the EA experience and to push through the difficulty of integrating.

I'm a Christian, and, one of the things she [a friend] said after [was], the Lord will lead you. And I feel like that has definitely been true. I feel like His hand was on me getting into this family very last minute, and the church that I found.

I skyped my mom one day. And she's like, 'you're also there to get the cultural experience and there's obviously a reason why you are there.' That was very helpful and just having that mindset....

When securing, success was based on determining how welcoming the community was and developing bonds with locals. A student staying in Leeds felt lucky that those in her housing block were welcoming: “...They were all, 'yea come out with us, come and meet us,' so, like, they were all very friendly, so that kind of eased that a little bit." Other students needed the welcoming spirit of the host community to alleviate their initial stress of being abroad. For example, despite the language barrier, a student in a Granada program was grateful for the local church choir she joined: "They are so excited for us to be there because we're so young and we're American. And so we're like fun and new to them... And people want to include outsiders."

Securing did not mean avoiding novelty. Instead, students processed novelty more cautiously by gradually identifying approaches to seeking novelty. As the literature on culture shock highlights, individuals use their cognitive skills to change their perceptions of the situation (Ward, Bocher, \& 
Furnham, 2001). As one student stated after being accepted by the host family and joining a predominately senior-aged church choir, "Yea, but I'm OK now, I've had very few emotional break downs, I'm pretty proud."

\section{Blending}

Blending involved experimenting with being a member of a host community, which often required displacing oneself: “...Everything that you know should be left behind in America in a way, and you have to be open to whatever it is now... [that is] the only way you can actually experience your study abroad.” Blending also included exhibiting knowledge of language, place, culture(s), customs, and people. Becoming knowledgeable and conversational about a destination's politics and social issues augmented students' ability to identify or relate to the host culture.

Students interpreted successful blending as being mistaken as a citizen of the host culture or "not stand[ing] out as someone who is American." Students who were unable to visibly blend in because of their physical features or poor language skills tried not to appear American. Similar to an ethnographer, they strived instead for a level of acceptance. Appearing American was interpreted as embarrassing or failing:

The people [other American students] who are speaking really loudly to me on the tram are not helping because that is not a thing you do in Germany. You don't speak on the tram at all. ...I do feel embarrassed and I do really struggle with trying to be like 'I'm not with them.'

I still feel like an American because I can just tell when people see me on the street they just know I'm not French and that's kind of been frustrating because I really want to blend in.

Conversely, mistaken identity, gaining skills to aide in mistaken identity, and authentic ${ }^{2}$ encounters with the host community were interpreted as measures of success:

The first time I 'fait le biseau'...with an actual French person... it was such an amazing experience. I felt like I finally made it, I am a real part of French culture. And it's moments like that when you sort of actually become a part of the culture and the society.

Blending also entailed "knowing a place" like the locals and doing what they do: "I like, walk everywhere, I love that... I mean there are busses I could take. I think if you don't walk you don't see as much as you can.” Becoming

\footnotetext{
${ }^{2}$ Wang's (1999) typology of authenticity was adopted to describe authentic experiences. Further discussion of his typology follows in the section, "Actually Being."
} 
familiar with the culture, traditions, and geography (e.g., knowing the directions) as well as the historical and social significance of the place were also important components of blending: "[W]hile I'm in Barcelona, I want to be able to say I know Barcelona. I just don't want to know, like, the basic stuff and, like, the touristy stuff. I want to know more than what you can read out of a book, like a travel book..." Students suggested learning about and knowing a place came from having conversations with residents about what it means to them, and walking or taking public transportation to internalize and learn about the place.

Students who chose to blend desired a connection and/or experimented with being a member of the host community. They intentionally pushed themselves outside of their comfort zones (Engberg \& Jourian, 2015). Their blending behavior resembled the "Intercultural Pygmalion," who attempts "to construct a certain image of the 'national self and other' and to copy certain national characteristics to become like the Other" (Dervin, 2013, p. 357). Students blended by copying the habits, language, behavior, and customs of the local people as if they were one of them. They compared and lauded people (e.g., their abilities, sensibilities, work ethic); social habits (e.g., how individuals form lines in public); and artifacts (e.g., food, stores, and rituals are better in the host culture). They tried on the culture or enacted an identity/role as a form of play. Being a tourist (a temporary member of the community) facilitated learning about the host community through a form of role-play. Hence, viewing students' playful behavior and decision to be a tourist as dichotomous to real work ignores the meaningfulness of being a tourist and its potential for contributing to meaning-making.

In summary, Securing and Blending were not fixed behaviors. Some students gravitated more toward one or the other, or after some time abroad, transitioned from one to the other. Students who saw personal development through Securing or Blending regarded their development with amazement:

I can live in a Spanish city for a semester and be OK. Which is still kind of blowing my mind" and "I feel more secure in myself. ... I think it's more the realization that I can put myself in an unfamiliar position or situation and still thrive...I feel like before I was kind of, like, trapped...I was kind of very limiting myself...

\section{Actually Being}

Actually Being grew from students' statements such as, "I am actually here" and "I'm actually speaking with real [local people].” The meaningmaking structure reflected the action in living and being human (Czerna, 2016; Kegan, 1982; Van Manen, 1990). It connoted students' transition from the 
imagined (e.g., pictures, media, daydreams about the pending experience) to the real. Living/being in this alternate reality abroad involved a level of conscious metacognition about mundane and extraordinary experiences that had a spiritual effect, making students feel humbled, confused or morally reassured. Cohen (1979) addressed this sense of being during travel. He purported that tourists vary along a continuum in terms of their sense of belonging or connection to a community or location. Some tourists, for example, enjoy traveling to temporarily get away; however, their sense of belonging remains with their home community. At the other end of the continuum, tourists' sense of belonging is less connected to their home; they experiment with other destinations and cultures by observing, taking part in, even experimenting with being part of that culture. In this study, students evoked similar positions along a continuum as they navigated actually being in the host destination, yet their navigation was also connected to the idea of authenticity or what is real or fake.

Both education and T\&T have been criticized for providing inauthentic and pseudo experiences. In the education literature, teacher and student authenticity (being one's true self in the classroom) and/or the authenticity of the classroom (i.e., professional communities are considered "real" and school communities may be misperceived as pseudo) have been challenged (Hung \& Chen, 2007). In the T\&T literature, starting with Boorstin (1951), tourist experiences have been referred to as superficial, shallow and inauthentic. MacCannell (1973), however, rebuffed Boorstin's assertions by arguing that tourists search for authenticity, but are unable to achieve it due to "staged authenticity" at the destination. And, Wang (1999) argued there is a continuum of authenticity ranging from objective (actual objects such as the Coliseum), to constructive (i.e., replicated objects), to existential (i.e., based on personal experience). While there are various definitions of authenticity, we adopted Wang's perspective of authenticity and used it to inform the discussion of the results that follow.

Some tourists struggle with their identity as a tourist. They try to disassociate themselves from the label of "tourist" as well as the mass tourism system (Week, 2012) by self-imposing restrictions on, for example, how and when they travel, yet are forced to negotiate them when they want to visit well-known tourist attractions (Jacobsen, 2000). EA students experienced similar struggles. Some indicated they did not want to do "touristy" inauthentic things such as taking tours and visiting popular attractions, yet visited the attractions anyway and, in some cases, found the informal learning environment preferable to the classroom:

I feel like in a classroom it's a lot more theory-based and people talking at you... Whereas, when I'm here [in] York... and they gave us a tour of 
the town [where] Mary Queen of Scots stayed'... like, I learned that in history in high school, but, it... went in one ear and out the other. But I feel like when experiencing something... it sticks better.

Other students assessed their experiences based on perceived authenticity of the source, putting the traditional classroom experience in a precarious position. A female student, for example, admitted to being much more attentive to the depictions of life in Granada, Spain from her host family's lived experience than those being presented in the classroom:

[L]earning [is] more interesting because when they [host family] are telling me about Spain or about their political situation. When I'm in my grammar class we're learning about the political situation because we need to learn some verb tense... it's just way more interesting because they are speaking it from their life.

The authenticity of the source-the host family—had much more credibility and personal connection to this student, elevating it over her classroom experience.

Another student preferred "those moments when you're actually talking to people... as opposed to just being in school," and reasoned, "I don't want to say they are more important than the school, but they offer a completely different perspective that you don't see in school." Thus, this student and others more highly valued the knowledge and information they garnered from natural (i.e., not contrived/authentic) conversations and interactions during EA. Having these natural encounters allowed them to connect with the world in a way they could not in a traditional classroom setting. Conversations with other members of the community (e.g., cashiers at local restaurants) and exchange students from other countries were considered equally authentic and beneficial.

For some students, classroom experiences interrupted the purpose of EA because they perceived that real knowledge about the people and the place was generated outside the classroom: “...the best way to get to know how people act is by people watching, and if you're stuck inside all day, you're never going to know how they act [so] it's really hard to have motivation for school work here." Some students felt restless or annoyed by having to learn in a traditional classroom setting, perceiving the process as "[taking] up a lot of time which is kind of annoying because you do want to explore and understand the culture more and do different things."

To others, classroom experiences were valuable under certain conditions. Students valued formal courses when they directly related to their interest in the host community's social structures and culture and enhanced 
their current experiences and understanding. One student felt relationships and conversations with her instructors were crucial to understanding the perspectives of educated Moroccans. She would have questioned the value of the course had it not been for her instructors: “...I can ask cultural questions of my professors and they know because it still is their culture. I think if my professors were American, I would almost not see the value of class." Another student appreciated in-the-moment discussions of world-impacting events, "whether it be Brexit or the migration crisis... [it] is brought up and we talk about it in real time... It's just such a fast past and interesting situation to be in and to be here."

"Actually Being” may be the central meaning-making structure for EA students. Students are literally in the moment, living the imagined, having a once in a lifetime experience, and getting answers and new insight from what they perceive to be authentic sources. Some students had waited so long for their EA experience that they had difficulty fathoming that they were living in the host location: "Every day that I wake up, I realize I'm living in France and I think, 'wow, I'm actually living this.' And it's just so surreal.” Being human, as Kegan (1982) posited, includes the occasional inability to compose meaning, which we often experience as the loss of composure. This sort of disbelief is associated with the powerful and complex feeling of awe.

\section{Living in a State of Awe}

Awe is a powerful, complex, and understudied emotion that is felt when confronted with a rich stimulus (Shiota, Keltner, \& Mossman, 2007) such as beauty, exceptional ability, the supernatural, or religion, virtue or threat. Keltner and Haidt's (Keltner \& Haidt, 2003) prototype of awe suggests vastness and accommodation are central to awe. "Vastness refers to anything that is experienced as being much larger than the self, or the self's ordinary level of experience or frame of reference” (p. 303). It is not limited by physical size and includes social size (e.g., fame or authority), loud sounds, shaking ground, or symbolic markers. Accommodation "refers to the Piagetian process of adjusting mental structures that cannot assimilate new experience” (p. 304). Awe requires both vastness and accommodation; for example, surprise involves accommodation without vastness. When experienced, "awe is associated with feelings of smallness of self and the presence of something greater than self”' (Shiota et al., 2007, p. 960).

Picard (2012) observed tourists' frustration with the "limitation and poverty of language to talk about [their tourism] experiences (p. 13)," relying on cliché terms (e.g. amazing, awesome, beautiful). This combination of the inability to accommodate and having limited word options to describe the magnitude of the experience was evident in EA students' stories. Vastness 
manifested itself in different ways for students. In some cases, they elicited feelings of disbelief or the inability to accommodate. Finally achieving the goal of studying abroad a student stated, "I'm still in disbelief that this is real. I also think with study abroad so much planning has gone into it you never really think you're ever going to get there... and finally it happens.” Disbelief was also evoked when students questioned their ability to study abroad: "I can't believe that I made this happen... it's, like, I'm here.” This was particularly true for students who were traveling without parents or siblings for the first time: "Trying to be an adult in a totally different country, [and] being, like, I'm here."

In addition, students began to see themselves as part of something larger, which was difficult for them to fathom. A student studying in Leeds said,

I guess it's this feeling of, like, there is so much more to this world than the little bubble I've grown up in in central Pennsylvania... I knew it's just a small drop of water in a big pond. But until you experience it you don't really get that, that sensation of... there is so much out there. And it's just like, I don't know, it's just kind of like, it's breathtaking.

According to Keltner and Haidt (2003), individuals may feel small or humbled (i.e., the effect of experiencing vastness) when visiting historical locations or traveling to new places. As one student in this study stated, "I love travelling [it] makes me feel small. Because I notice there is so much in the world beyond what I know...So, it’s really exciting in that regard and really humbling.”

Awe in this EA context operated just beneath the surface of the seemingly mundane to the overtly interesting occurrences that bombarded students. Awe appeared in passing, unprompted instances such as those described by students in Leeds, Karlsruhe and Rome: “...Sometimes it hits me and I'm kind of taken aback...," "Yea (laughing), sometimes I'm walking down the street and I'm, like, I can't believe I'm living here by myself, what is going on?” and

[I started] crying and it was that moment of 'I am really here.' Like I am looking at St. Peter's Basilica in the middle of my run with the sun setting behind it. And like this is home for me right now. That was definitely one of those, moments...but [it kind of] hit me when I was running through it [the park].

When and what triggered awe was highly personal. At times it was evoked by a particular event, interaction, or realization: “...At the Coliseum I would think about the history that happened there and it's so weird as you're standing there and you're like 'oh my Gosh' what even is this place?” At other times the confirmation of or opposition to student's values or beliefs activated 
awe. In describing her admiration of Germany's reaction to its Nazi past, a student said,

Germans are very, very cognizant of their national history. I really like that about them because I don't think Americans are. So, I think, the tour we had...explaining all this symbolism that went into their government building was really exciting for me and sort of, in-awe, because I sort of wish we're a little more like that.

Many students, however, had difficulty making sense of their experience. They struggled to find the words to describe awe-evoking moments: "I'm trying to think of the word... I want to say almost, like, 'in awe' kind of, like, 'wow,'... It's like mind-boggling... I can't fully wrap my mind around that." Students often ended their attempts to describe their experiences with superlatives such as, "amazing” or "breathtaking," or they apologized saying, "I don’t know, does that make sense?”

\section{Discussion and Implications}

Researchers have focused on "what" (i.e., content, the change in what students think) rather than "how" (i.e., structure, understanding how students think) when examining students' meaning-making in EA. We focused on "how" by adopting a CGT approach, which allowed us to document how students perceive of and interpret their EA experience. This approach revealed that students process their experience through seeking and gaining knowledge about the world. Our results led to the proposed Education Abroad Meaning Making (EAMM) Framework.

The EAMM Framework represents our first attempt to highlight how students process and make sense of their EA experience(s) sans intervention. The EAMM Framework illustrates how students make sense of experiences through four meaning-making structures- "Seeking Novelty," "Securing and Blending," "Actually Being," and "Living in a State of Awe." These structures emerged from students' responses to in-depth interviews. A post-data analysis review of the literature in EA, education, student development, and T\&T, in line with a grounded theory design, provided support for the structures that comprise the EAMM Framework.

Novelty, which is understudied in EA research, has received a great deal of attention in tourism studies. It is well known as a motivation for travel and a stimulus for curiosity and exploration, two qualities lauded by higher education professionals and recognized as necessary for creativity and innovation. In the EAMM Framework, "Seeking Novelty" is the foundation of how students make sense of their EA experience. As Falk et al. (1978) suggest, 
educators must take advantage of this: "novelty... is an extremely important educational variable. [Educators need to] harness this variable to enhance rather than hinder [their] educational objectives (p.133).” Zull (2012, p. 184) agrees; suggesting that students learn best when engaged in novel and interesting experiences, such as EA. The challenge facing EA professionals is that they and students do not agree on what are appropriate novel experiences. EA professionals often do not consider play, entertainment, exotic food, or travel as suitable learning opportunities (Zull, 2012). The findings of this study, presented through the EAMM Framework, and those presented by other researchers (Bos et al., 2015; Falk, Ballantyne, Packer, \& Benckendorff, 2012; Mitchell D., 1998; Werry, 2008), suggest EA practitioners and faculty must reconsider their perspectives and continue to conduct further research on novel learning experiences.

"Securing and Blending" drew out aspects of identity not traditionally tackled in EA. Like professionals, students adopted the anti-tourist/tourism attitudes, yet their responses suggested that meaningful and educational experiences took place during their T\&T experiences (i.e., weekend excursions, visiting attractions). More research is needed to understand the incongruence between students' attitudes and their behavior, particularly how they navigate between who they claim to be (or not be) and what they do and what they learn during EA. Further, researchers should consider how the tourist identity, which may be projected onto students, affects them and the experience, especially "Blenders" who aim to be mistaken for a local.

“Actually Being” introduced important ideas often overlooked in EA research. For example, students highly valued knowledge, learning, and education from authentic, non-contrived experiences with locals in and out of the classroom. They also said the experience of being there provided a visceral connection to the location which made them examine who they are and how they live in comparison to living in the United States. This included interactions with actual objects (e.g., Sagrada Familia, Reichstag) and constructed or replicated objects (e.g., Malham Cove, Yorkshire England where scenes from Harry Potter were filmed). Thus, as tourism researchers have argued, authenticity is subjective and can be conceived of differently. Educators need to be open-minded to and accepting of the authentic and educative possibilities in non-traditional experiences. Using grounded theory, phenomenology or other interpretive approaches to continue to understand students' authentic lived experience while abroad will not only extend theory and validate the EAMM, but continue to inform how and what should be provided for EA students in general and in their curriculum.

"Seeking Novelty," "Securing and Blending," and "Actually Being” are the impetus for the high emotions experienced during EA. Together they 
conjure feelings of disbelief, joy, and humility, all of which are captured when experiencing the powerful emotion of awe. To date, few scholars have examined students' emotions, such as awe, in a formal educational travel context (Savicki \& Price, 2015; Zull, 2012) with the exception of Engberg and Jourian (2015), who studied intercultural wonderment in study abroad. Failure to study emotions students experience during their EA experience is problematic. First, emotion cannot be separated from cognitive or intellectual development. Second, T\&T and temporarily living in a new culture is disruptive to normal patterns of thinking, which students value (Zull, 2012). This is a problem if evidence of success is based on normal classroom settings. Hence, more interdisciplinary research examining travel, emotions, and learning in a formal educational context is needed to better understand students' EA experiences and to improve program development.

Lastly, an indicator of awe is the inability to articulate the meaning or significance of an experience. Students and tourists use terms like awesome, fantastic, and amazing because they lack the vocabulary to adequately describe their experience (Picard, 2012). Students said their EA experience "was awesome," and when asked to explain, noted that many of their experiences (including travel) provided credible opportunities for learning. Hence, misinterpreting these overused superlatives/cliché statements to mean that students had frivolous, non-educative experiences can lead practitioners to overlook important psychological processes which may or may not relate directly to an academic course, but are certainly linked to the purposes of higher education.

Trustworthiness and credibility of the EAMM framework were established by seeking students' input during post-experience interviews. Students reviewed and concurred with the Framework but admitted, "Yes, I agree with that...but I don't ever think about it like that.” Students also provided personal feedback as to how the Framework specifically applied to them and other students during their EA experience. For example, a student expressed that fellow students on his program were "Blenders," but felt during his program he did not need to blend: "I'm American, but I still want to do fun things...take in what's happening around me, take in the culture and let it like, hit my life.” Feedback also illustrated the Framework's ability to capture the variability in student experiences. For example, a student stated,

I think [I felt] awe, but not in a sense of 'oh my God, I never even considered this before,' not in a mind-blowing way, but awe as in I respect that I'm in a really cool place or ...that this really cool thing is happening to me. 
Considering the curiosity-provoking and awe-inspiring formal educational travel experiences described by students in this study, traditional approaches to conceptualizing the EA curriculum may be outdated. Dewey (1916) argued for experiential education prompted by natural tendencies to explore and give expression to joyous emotion to reduce the artificial gap between school and life. Illustrating the nexus between travel and learning for tourism managers, Falk et al. (2012) proposed viewing travel through Aristotle's three concepts of wisdom; techne (skills), episteme (knowledge) and phronesis (practical wisdom) to demonstrate how travel contributes to learning. Acknowledging EA, Falk et al. suggested EA epitomizes phronesis. Ascribing to the three concepts of wisdom as a philosophical base soundly expands upon Dewey's notion of experiential education and provides a useful platform for the development of learning and educative experiences during EA.

The EAMM Framework illustrates that students process their EA experiences through meaning-making forms that may not be present in their regular environment. Recognizing this and that students are seeking primary knowledge about their world from new experiences (based on their perception of new) as well as personal and authentic experiences, and are living in a state of awe, provides more insight into student learning. With this knowledge, we suggest considering Schneider's (Schneider, 2003) Awe-based Inquiry in which the concept of awe is infused in to the curriculum (Schneider, Pierson, \& Bugental, 2014). For example, in the classroom, faculty could begin by investigating "how cultures throughout history affirmed or suppressed a sense of awe" or by examining the

relevance of a given a subject to students' lives... their dreams, or visions of making an impact on the future world. Or... by introducing awe, the thrill and anxiety, humility, and wonder of living, as a concept and relating that concept to a given subject area...” (Schneider, 2003, p. 138).

The EA experience is ideal for awe-based inquiry. Students' personal experiences can drive the content of the curriculum and more naturally connect cognitive and affective aspects of learning, which may lead to greater retention, transformation and inspire vision in students, thus impacting their future.

\section{Limitations and Future Research}

Despite the new insight to students' EA experience, study limitations must be acknowledged. First, conducting interviews from afar was challenging in terms of scheduling interviews between time zones, securing Wi-Fi (sometimes access was limited and/or signals were weak), time available for the interview (none of the interviews lasted more than 70 minutes), and 
aiming not to intrude on students EA experience. Regarding interview length, setting limits for in-depth interviews for CGT is arbitrary (Charmaz, 2014), yet it does take time during in-depth interviews for respondents to confront and reveal their perceptions (Crompton, 1979). Thus, multiple interviews that are longer in duration and repeated (e.g., over the course of three to four-months) should be used to gain further insight to how students think about EA while it is being experienced. Second, the sample was obtained from students attending one institution of higher education who were participating in various types of EA programs. It is conceivable that students from different institutions may have different meaning-making strategies and ways of describing them. Thus, researchers should replicate this study at various types of institutions and with different types of EA programs. Despite these primary limitations, the results of this study do provide new theoretical and practical insights to meaning-making for students participating in EA.

In the future researchers should attempt to verify the meaning-making structures uncovered in this study, identify if there are additional structures to include in the Framework, and continue "filling out" the existing structures. For example, there may need to be an identity structure that accounts for pretrip identity forms (e.g., sexuality, nationality). In addition, a secondary or transitional framework may need to be developed to account for changes in students' meaning-making structures (i.e., student development) throughout the program. As mentioned earlier, students may begin by securing but may transition to blending as time progresses.

More theoretical sampling is needed to ensure that concepts related to the EAMM Framework have been identified and descriptions are robust. To do this, existing interviews must be reexamined, follow up interviews must be conducted with past interviewees, and interviews should be conducted with more EA participants in situ. CGT takes patience, it is not uncommon for this process to take several years (Charmaz, 2014).

In time an EAMM scale could be created and used in conjunction with in-depth interviews, motivation and expectation scales, and/or the Student Development Task and Lifestyles Assessment (Wachs \& Cooper, 2002). This could take place prior to, during, and after students' EA experience to fully examine their emotional, socio-cultural, and cognitive/structural development. Better understanding what students bring to the educational setting will result in improved experiences and a stronger connection to the content and learning process. Steps of this nature have been taken in traditional educational settings (Ambrose et al., 2010; Bean \& Eaton, 2000) and should be considered in EA. 


\section{Conclusion}

The primary research question in this study was, "How do students make meaning during their EA experience?” We answered this question using a CGT approach, which involved in-depth interviews. The EAMM Framework was created to highlight the meaning-making structures students use when making sense of their EA experiences. This Framework, which includes "Seeking Novelty," "Blending and Securing," "Actually Being," and "Living in a State of Awe," provides needed insight into students' experience on EA and has implications for pre- and post-experience advising and program development. The study results led to the development of one of the few, if not only, theoretical frameworks addressing how students make sense of their EA experience. The Framework also has several practical implications.

\section{Author Biographies}

Dr. Kristin Thomas is an Assistant Professor in Recreation, Park, and Tourism Management (RPTM) at Penn State University, USA. Kristin connects theory and practice in the classroom by applying years of experience as a practitioner in curricular and co-curricular program development (domestic and international) with her research on student development, learning, and sensemaking during travel and recreational experiences. She is also the RPTM Faculty Coordinator for the Meeting and Events Management Certificate.

Dr. Deborah Kerstetter, Professor Emerita of Recreation, Park, and Tourism Management at The Pennsylvania State University, USA, has maintained two primary lines of research: tourist decision-making behavior and tourism impact, primarily from a sustainability perspective. Her research, much of it conducted with her students, has been revealed through more than 100 peerreviewed articles, multiple book chapters, and over 150 academic presentations.

\section{References}

Allen, H. W. (2009). What Shapes Short-Term Study Abroad Experiences? A Comparative Case Study of Students' Motives and Goals. Journal of Studies in International Education, 14(5), 452-470.

Ambrose, S. A., Bridges, M. W., DiPietro, M., Lovett, M. C., Norman, M. K., \& Mayer, R. E. (2010). How learning works: seven research-based principles for smart teaching (Vol. 1st). San Francisco, CA: Jossey-Bass.

Andereck, K., McGehee, N. G., Lee, S., \& Clemmons, D. (2011). Experience expectations of prospective volunteer tourists. Journal of Travel Research, 51(2), 130-141. 
Baxter Magolda, M. (2008). Three Elements of Self-Authorship. Journal of College Student Development, 49(4), 269-284. https://doi.org/10.1353/csd.0.0016

Baxter Magolda, M., \& King, P. (2007). Interview strategies for assessing self-authorship: constructing conversations to assess meaning making. Journal of College Student Development, 48(5), 491-508.

Baxter Magolda, M., \& King, P. (2012). Assessing meaning making and self-authorship: theory, research, and application (Vol. 38). San Francisco, CA: Wiley/Jossey-Bass.

Bean, J., \& Eaton, S. B. (2000). A psychological model of college student retention. In J. Braxton M. (Ed.), Reworking the student departure puzzle (pp. 48-61). Nashville: Vanderbilt University Press.

Berlyne, D. E. (1950). Novelty and curiosity as determinants of exploratory behaviour1. British Journal of Psychology. General Section, 41(1-2), 68-80.

Bodycott, P. (2015). Intragroup conflict during study abroad. Journal of International Students, 5(3), 244-259.

Bos, L., McCabe, S., \& Johnson, S. (2015). Learning never goes on holiday: An exploration of social tourism as a context for experiential learning. Current Issues in Tourism, 18(9), 859-875.

Cardon, P. W., Marshall, B., \& Poddar, A. (2011). Using typologies to interpret study abroad preferences of American business students: Applying a tourism framework to international education. Journal of Education for Business, 86(2), 111-118.

Charmaz, K. (1990). "Discovering” chronic illness: Using grounded theory. Social Science Medicine, 30(11), 1161-1172.

Charmaz, K. (2014). Constructing grounded theory. Sage.

Cohen, E. (1972). Toward a sociology of international tourism. Social Research, 39(1), 164., 39(164-182).

Cohen, E. (1979). A Phenomenology of Tourist Experiences. Sociology, 13(2), 179-201. https://doi.org/10.1177/003803857901300203

Creswell, J. W. (2012). Qualitative inquiry and research design: Choosing among five approaches. Sage.

Crompton, J. L. (1979). Motivations for pleasure vacation. Annals of Tourism Research, 6(4), 408-424.

Czerna, M. (2016). Jordan Peterson: Phenomenology of Being. Retrieved June 18, 2017, from https://www.youtube.com/watch?v=7jYR5wbElWQ\&list=LLVIWeixZTrh2uZrHbdblD Pw\&t=1490s\&index $=17$

Dervin, F. (2013). Rethinking the acculturation and assimilation of "others" in a "monoculutral" country forms of . Journal of Intercultural Studies, 34(4), 356-370.

Engberg, M. E., \& Jourian, T. J. (2015). Intercultural wonderment and study abroad. Frontiers: The Interdisciplinary Journal of Study Abroad, 25.

Falk, J. H., Ballantyne, R., Packer, J., \& Benckendorff, P. (2012). Travel and learning: A neglected tourism research area. Annals of Tourism Research, 39(2), 908-927.

Falk, J. H., Martin, W. W., \& Balling, J. D. (1978). The novel field-trip phenomenon: Adjustment to novel settings interferes with task learning. Journal of Research in Science Teaching, 15(2), 127-134.

Geiser, J. D. (2015). A sociocultural investigation of identity: How students navigate the study abroad experience. Journal of College Student Development, 56(6), 637-643.

GRS Deutschland. (n.d.). Nuclear fusion and nuclear fusion- what exactly happens in these procsses. Retrieved from https://www.youtube.com/watch?v=xrk7Mt2fx6Y 
Hall, T., Gray, T., Downey, G., Sheringham, C., Jones, B., Power, A., \& Truong, S. (2016). Jafari and transformation: A model to enhance short-term overseas study tours. Frontiers: The Interdisciplinary Journal of Study Abroad, 27(April), 33-46.

Hung, D., \& Chen, V. D.-T. (2007). Context-process authenticity in learning: Implications for identity enculturation and boundary crossing. Educational Technology Research and Development, 55(2), 147-167.

Jacobsen, J. K. S. (2000). Anti-tourist attitudes: Mediterranean charter tourism. Annals of Tourism Research, 27(2), 284-300.

Kegan, R. (1982). The evolving self: problem and process in human development. Cambridge, Mass: Harvard University Press.

Keltner, D., \& Haidt, J. (2003). Approaching awe, a moral, spiritual, and aesthetic emotion. Cognition \& Emotion, 17(2), 297-314.

Kiely, R. (2004). A chameleon with a complex: Searching for transformation in international service-learning. Michigan Journal of Community Service Learning, 10(2).

Kinginger, C. (2009). American students abroad: Negotiation of difference? Language Teaching, 43(2), 216-227.

Lahey, L., Felix, S., Goodman, R., Kegan, R., \& Souvaine, E. (2011). A guide to the subjectobject interview: Its administration and interpretation.

Lee, T.-H., \& Crompton, J. (1992). Measuring novelty seeking in tourism. Annals of Tourism Research, 19(4), 732-751.

Meyer-Lee, E., \& Evans, J. (2007). Areas of study in outcomes assessment. A Guide to Outcomes Assessment in Education Abroad, 61-70.

Mitchell D., R. (1998). Learning through plan and pleasure travel: Using play literature to enhance research into touristic learning. Current Issues in Tourism, 1(2), 176-188.

Nyaupane, G., Paris, C. M., \& Teye, V. (2010). Why do students study abroad? Exploring motivations beyond earning academic credits. Tourism Analysis, 15(2), 263-267.

Pagano Laura, M. R. (2009). Beyond reflection through an academic lens: Refraction and international experiential education. Frontiers: The Interdisciplinary Journal on StudyAbroad, XVIII, 217-229.

Pearce, P. L., \& Lee, U.-I. (2005). Developing the travel Career approach to tourist motivation. Journal of Travel Research, 43(3), 226-237.

Picard, D. (2012). Tourism, awe and inner journeys. Emotion in Motion: Tourism, Affect and Transformation, 1-20.

Relyea, C., Cocchiara, F. K., \& Studdard, N. L. (2008). The effect of perceived value in the decision to participate in study abroad programs. Journal of Teaching in International Business, 19(4), 346-361.

Ritchie, B., Cooper, C., Hall, C. M., \& Timothy, D. (2009). Managing educational tourism. Clevedon, UK: Channel View Publications.

Savicki, V., \& Price, M. V. (2015). Student Reflective Writing: Cognition and Affect Before, During, and After Study Abroad. Journal of College Student Development, 56(6), 587-601.

Schneider, K. J. (2003). The fluid center: An awe-based challenge to humanity. Journal of Humanistic Psychology, 43(3), 133-145.

Schneider, K. J., Pierson, J. F., \& Bugental, J. F. T. (2014). The handbook of humanistic psychology: Theory, research, and practice. Sage Publications.

Shiota, M. N., Keltner, D., \& Mossman, A. (2007). The nature of awe: Elicitors, appraisals, and effects on self-concept. COGNITION \& EMOTION, 21(5), 944-963. https://doi.org/10.1080/0269993060923668 
Sutton C., R., Miller N., A., \& Rubin L., D. (2007). Research design in assessing learning outcomes of education abroad programs. In M. Bolen C. (Ed.), A guide to outcomes assessment (pp. 23-59). Lancaster, PA: Forum on Education Abroad.

The Forum on Education Abroad. (2017a). State of the field 2017. Carlisle, PA.

The Forum on Education Abroad. (2017b). Who we are. Retrieved October 31, 2018, from https://forumea.org/about-us/who-we-are/

Twombly, S. B., Salisbury, M. H., Tumanut, S. D., \& Klute, P. (2012). Study Abroad in a New Global Century: Renewing the Promise, Refining the Purpose, ASHE Higher Education Report. John Wiley \& Sons.

Van Manen, M. (1990). Researching lived experience: Human science for an action sensitive pedagogy. Suny Press.

Vande Berg, M., Paige, M., \& Lou, K. H. (2012). Student learning abroad: What our students are learning, what they are not, and what we can do about it. Stylus Publishing.

Wachs, P. M., \& Cooper, D. L. (2002). Validating the student developmental task and lifestyle assessment: A longitudinal study. Journal of College Student Development, 43(1).

Wang, N. (1999). Rethinking authenticity in tourism experience. Annals of Tourism Research, 26(2), 349-370.

Ward, C., Bocher, S., \& Furnham, A. (2001). They psychology of culture shock (Second). Philadelphia: Routledge.

Week, L. (2012). I am not a tourist: Aims and implications of "traveling." Tourist Studies, 12(2), 186-203.

Weisler, A., \& McCall, R. R. (1976). Exploration and play: Resume and redirection. American Psychologist, 31(7), 492.

Werry, M. (2008). Pedagogy of/as/and tourism: Or, shameful lessons. Review of Education, Pedagogy, and Cultural Studies, 30(1), 14-42. Retrieved from http://dx.doi.org/10.1080/10714410701566207

Williams, S. (2018). Personal Communication.

Wong, E. D. (2015). Beyond “it was great"? Not so fast! The Interdisciplinary Journal of Study Abroad, XXVI(Fall), 121-135.

Zull, J. (2012). The brain, learning, and study abroad. In M. Vande Berg, M. Paige, \& K. H. Lou (Eds.), Student learning abroad: What our students are learning, what they're not, and what we can do about it. Sterling: Stylus Publishing. 